\title{
An Introductory of Mental Arithmetic Using Interactive Multimedia for Pre-School Children
}

\author{
Siti Zulaiha Ahmad (Corresponding author), Arifah Fasha Rosmani, Mohammad Hafiz Ismail \& Suraya \\ Mohammad Shakeri \\ Department of Computer Science \\ Faculty of Computer and Mathematical Sciences \\ Universiti Teknologi MARA, 02600 Arau, Perlis, Malaysia \\ Tel.60-012-760-5169 E-mail: sitizulaiha@perlis.uitm.edu.my
}

\begin{abstract}
Arithmetic is an important skill to learn at an early age. However, teaching arithmetic to pre-school children can be challenging as children around that age have short attention span and prefer to engage in interactive activities. Thus, the purpose of this study is to incorporate multimedia elements into mathematical learning to make it more interactive and exciting to the children. The contents have been specifically designed to visualize the introduction of numbers and to encourage children's interaction by drawing their attention to the courseware. The result revealed that the students have shown significant improvement over the mental arithmetic approach after being subjected to a typical classroom test. This concludes that the mental arithmetic using interactive multimedia could enhance learning experience for pre-school children.
\end{abstract}

Keywords: Multimedia application, Mental Arithmetic, Mathematics, Children

\section{Introduction}

Learning mathematics is crucial and vital because it develops cognitive thinking in young children and it is a challenging task for parents and teachers to educate them. One of the alternatives is to provide interesting learning environment to the children, by adapting interactive multimedia application. Previous research showed that interactive multimedia influenced the effectiveness of learning process (Evans \& Gibbons, 2007).

Teachers need to implement a different learning approach which includes elements of sound, text, graphic and animation in order to provide a better learning approach. These elements have been proven to be more interactive, therefore multimedia learning will improve students' performance and enhance the teaching and learning process as stated by Nott, Nott, and Lee, (2000) and Paschke and Paschke, (2005). In traditional method, most of the children use exercise books as their source of information. If this method is being used as a single approach in classrooms then it will be difficult to build their understanding and imagination towards mathematical subject matter. Resnick (2007) believes that this method can cause them to be easily distracted and hard to pay attention, resulted by a dull and boring environment. The lack of attractive approaches in children's learning process could affect their insight. Tedious learning environment could cause the children to lose interest in understanding mathematical problem solving. Therefore, a Mathematical Learning Courseware is developed to cater to this problem.

In order to simplify the learning process we have adapted a part of mental arithmetic technique to visualize it in a simple way. The introduction of this technique is purposely as a platform for the children to be in mainstream education system.

The rest of this paper is organized as follows: The second section introduces the mental arithmetic technique and mathematical learning using multimedia, and in the next section, focuses on the method of the study which described the construction procedure. The paper concludes with the discussion of the result.

\section{Mathematical Learning}

Learning is an active process of integrating information with pre-existing knowledge (Ullrich, 2008). Mathematics is a living subject which seeks to understand patterns that permeate both, world around us and the mind within us (Schoenfeld, 1992). It is important to learn mathematics' subject in order to expand problem solving skill and creative thinking.

\subsection{Mental Arithmetic Technique}

Mental arithmetic is defined as the act of adding numbers together, multiplying them and the like, in your mind, without writing them down (Longman, 2010). This technique applies primarily to the simple addition, 
subtraction, multiplication and division facts with single-digit numbers. Arithmetic involves various cognitive processes and strategies depending on types of operation, numerical symbols used and so on, as evidenced by double dissociations found in brain-damaged patients with impairment of function (Anderson et al., 1990).

This technique provides basic universal method to learner such as; fingering (Chong, 1996) and brain (Cheah, 2006). According to Cheah (2006), children can start counting with imagination in their brain, then movements to the real fingers. This method shows that children are able to calculate quickly and accurately.

According to Ayshea (2009) mental arithmetic is needed in children's learning to establish the cognitive thinking in mathematics subject. Cognitive thinking is important because, first it influences the ability of children to solve problem; second it develops creative thinking and third it attracts interest of children. The other benefits are children can build confidence in solving mathematical problems and become flexible thinkers (Rheta, 2001).

\subsection{Mathematical Learning using Interactive Multimedia}

Computer technology has become the main aspiration in the development of children and early education of children. The evolution of computer technology has enabled learning process to be conducted in an innovative way in which it could generate more interesting and attractive methods. One of the innovations in early children education is to incorporate multimedia elements as the learning tool.

Neo (2004) and Tolhurst (1995) both define multimedia as the media and contents that uses a combination of elements such as text, graphic, animation and sound. The use of multimedia elements is to make learning process more interactive and interesting. Multimedia can help gain one's attention, increase retention and improve understanding. It integrates multi-sensory interactive application or presentation to convey a message or information to an audience. Furthermore, interactive multimedia has proven to influence the learning process enhancement (Evans \& Gibbons, 2007).

\section{Methodology}

The study was conducted based on the research model as represented by Figure 1. The first step involves information gathering activities in order to gain insights of the target audience as well as the classroom environment, where the multimedia courseware will be deployed. These include activities such as interviewing the teachers and observing the children in classroom during learning process. Special attention is given towards children's behavior and reaction during mental arithmetic lessons in order to have better understanding on reasons that motivates the children during the learning process.

This information is later used as input in "Storyboard Design" where multimedia elements are incorporated into classroom lessons. In this phase, the graphics and sounds are carefully chosen to stimulate the children's learning experience and to entertain them. The design of the storyboard closely follows Courseware Architecture as shown in Figure 2. The storyboard would then undergo a number of revisions based on the researchers' and teachers' input until the final version is produced.

The design is translated into multimedia application in "Courseware Construction". Here, the multimedia elements, together with the courseware activities are put together using multimedia packages software (Adobe Flash, Adobe Photoshop and SoundForge). The resulting application is then pre-tested to ensure it is free of glitches before it is used by the target audiences.

The final step consists of two parts; the goal of measuring the performance and the courseware's acceptability among the targeted audiences. The first part is called Pre-Test where the children will be subjected to the normal learning process by their teachers and the second part is called Post-Test, where the students will be induced with the mental arithmetic learning process. After that the teachers will be given questionnaires consist of 22 Likert Scale Based questions. The result is then analyzed to determine the acceptance rate of the application.

\section{Courseware Architecture}

Figure 2 shows the courseware architecture of the Mathematical Learning Courseware. First of all, users were exposed to the numbers and operation examples. Then, they continued with the provided exercises in the application. Mental arithmetic technique is applied in the operation and subtraction activities. The courseware composes of four main modules: 1) Number Introduction, 2) Arithmetic Operation, 3) Exercises, and 4) Quizzes.

\subsection{Introduction of Numbers}

Figure 3 shows the introduction of number module. This module presents numbers starting from number one until number nine. The children can identify and read numbers together with the character, 'Sue'. Furthermore, the objects representing the number is provided with animation and spelling. 


\subsection{Mental Arithmetic Techniques}

By adapting this technique, we used the brain and fingering approach in calculation as shown in Figure 4. The children can visualize the number in their brains and continue counting with their fingers. This technique teaches children to counting quickly and accurately (Cheah, 2006).

\subsection{Subtraction Operation}

An example of subtraction operation with animation is provided. For example, in Figure 5 the ice cream is eaten bit by bit. An instruction on the subtraction operation will be played.

\subsection{Quiz}

In order to test the children's understanding level, we provide some quizzes to test them. Children will try to count and apply mental arithmetic techniques for addition and subtraction quizzes. The children need to select the correct button after they finish calculating. If the children select the correct answer, they will get an ice-cream as a reward such as in Figure 6.

\section{Result and Discussion}

We have conducted two types of testing which are a series of experiments and user acceptance test. The experiment was done to measure the supportiveness of Mathematical Courseware application as a tool to teach children learning mathematic. These experiments have two phases which are the pre-test phase and the post-test phase. The experiment is used to observe the result of application before (pre-test) and after (post-test) the exploration. There were 11 participants involved in the experiments. These respondents are preschooler aged 5 to 6 years old from a kindergarten in Arau, Perlis.

In the pre-test phase, children were given the traditional exercise to test their understanding. They did the exercise and calculated the operation using common approaches. The experiments were continued with the second phase which was the post-test. At this phase, children were given the chance to explore and use Mathematical Courseware application and were guided by the researcher. At the end of the second phase session, we tested the participants with the quizzes provided in the application.

User acceptance testing has been done involving the end user to gain their confidence towards the application in supporting the children's learning. The testing involved seven teachers from a kindergarten in Arau, Perlis and 25 UiTM students. The users have evaluated the application based on the objective of the application, content and structure, navigation, interactivity, interface design, and sound of the application.

Below are the results for the experiments and user acceptance test. Based on the experiments the result shows that the mean score for pre-test is 13.36 and post-test is 14.5 (Figure: 8). Whereas, in the user acceptance test it shows that $59 \%$ of the respondents strongly agrees that the application has achieved its objectives. Another $41 \%$ agrees on the achievement, see Figure: 9.

\section{Conclusion}

The idea for mathematical courseware application is based on the mental arithmetic techniques. Mental arithmetic technique is trusted to increase counting and problem solving skills in mathematics subject.

From user acceptance testing, we conclude that this application has achieved its target to be a helpful tool to support children in learning mathematics. Furthermore, it is believed that the Mathematical Courseware application could assist teachers in educating children to learn mathematics especially on mental arithmetic techniques. This shows that the multimedia application has a significant impact in increasing the children's understanding toward the mental arithmetic techniques.

\section{References}

Ayshea J. (2009). Comparing research into mental calculation strategies in mathematics education and psychology. Proceedings of the British Society for Research into Learning Mathematics, 29(1).

Cheah \& Ong. (2006). Perbandingan kebolehan menyelesaikan masalah matematik antara murid yang belajar abakus-aritmetik mental dengan murid yang tidak belajar abakus-aritmetik mental. Jurnal Pendidik dan Pendidikan, Universiti Sains Malaysia, 21, 85-100.

Chong T. (1996). A case for fingering in mental arithmetic. The Mathematics Educator, Association of Mathematics Educators, 1(2), 129-134.

Evans C. \& Gibbons N. J. (2007). The interactivity effect in multimedia learning, Computer and Education. ACM, Elsevier Science, 49 (4) (December 2007). 
Longman. (2010). Dictionary of Contemporary English. United Kingdom, Pearson Education Limited.

Paschke J. \& Paschke C. (2005). Flashing into a child's mind: The educational impact of children's multimedia on learner satisfaction. Unpublished dissertation, Mercer University.

Nott, C., Nott, G. \& Lee, C.C. (2000). Simply simulation: an interactive cd-rom-based approach for learning simulation concepts. Proceedings of the 2000 Winter Simulation Conference, Society for Computer Simulation International, 2000.

Resnick, M. (2007). All I Really Need to Know (About Creative Thinking) I Learned (By Studying How Children learn) in Kindergarten. Proceedings of the 6th ACM SIGCHI Conference on Creativity \& Cognition, 1 -6 .

Rheta, N. (2001). Mental Mathematics beyond the middle school: why? what? how?. The National Council of Teachers of Mathematics, 442-446.

Schoenfeld, A. H. (1992). Learning to think mathematically: problem solving, metacognition, and sense-making in mathematics. In D. Grouws (Ed.), Handbook for Research on Mathematics Teaching and Learning. New York: MacMillan.

Tolhurst, D. (1995). Hypertext, hypermedia, multimedia defined?. Educational Technology, 35(3), 21-6.

Ullrich (2008). Why Web 2.0 is good for learning and for research: Principles and prototypes. WWW 2008, Beijing, China.

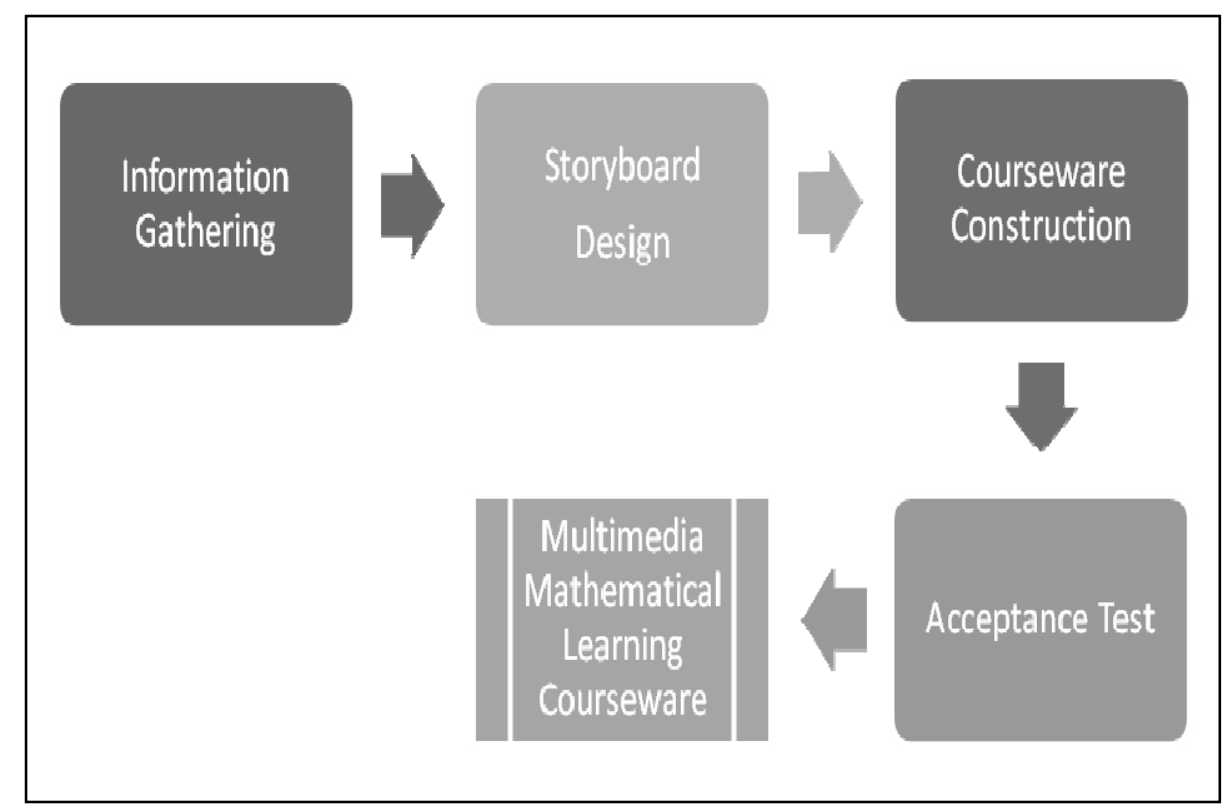

Figure 1. Research Model 


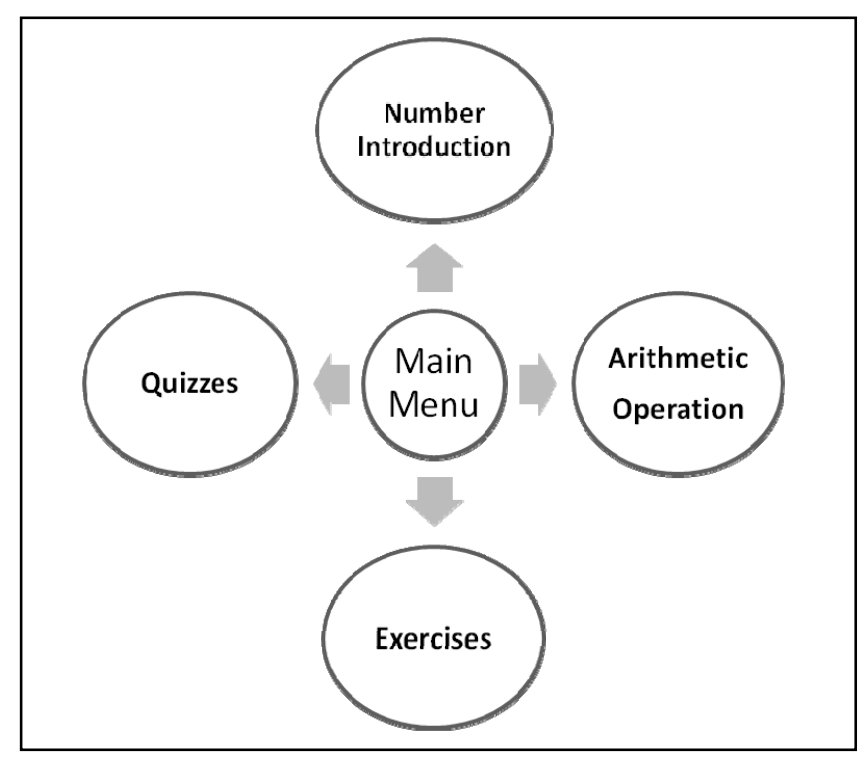

Figure 2. Courseware Architecture

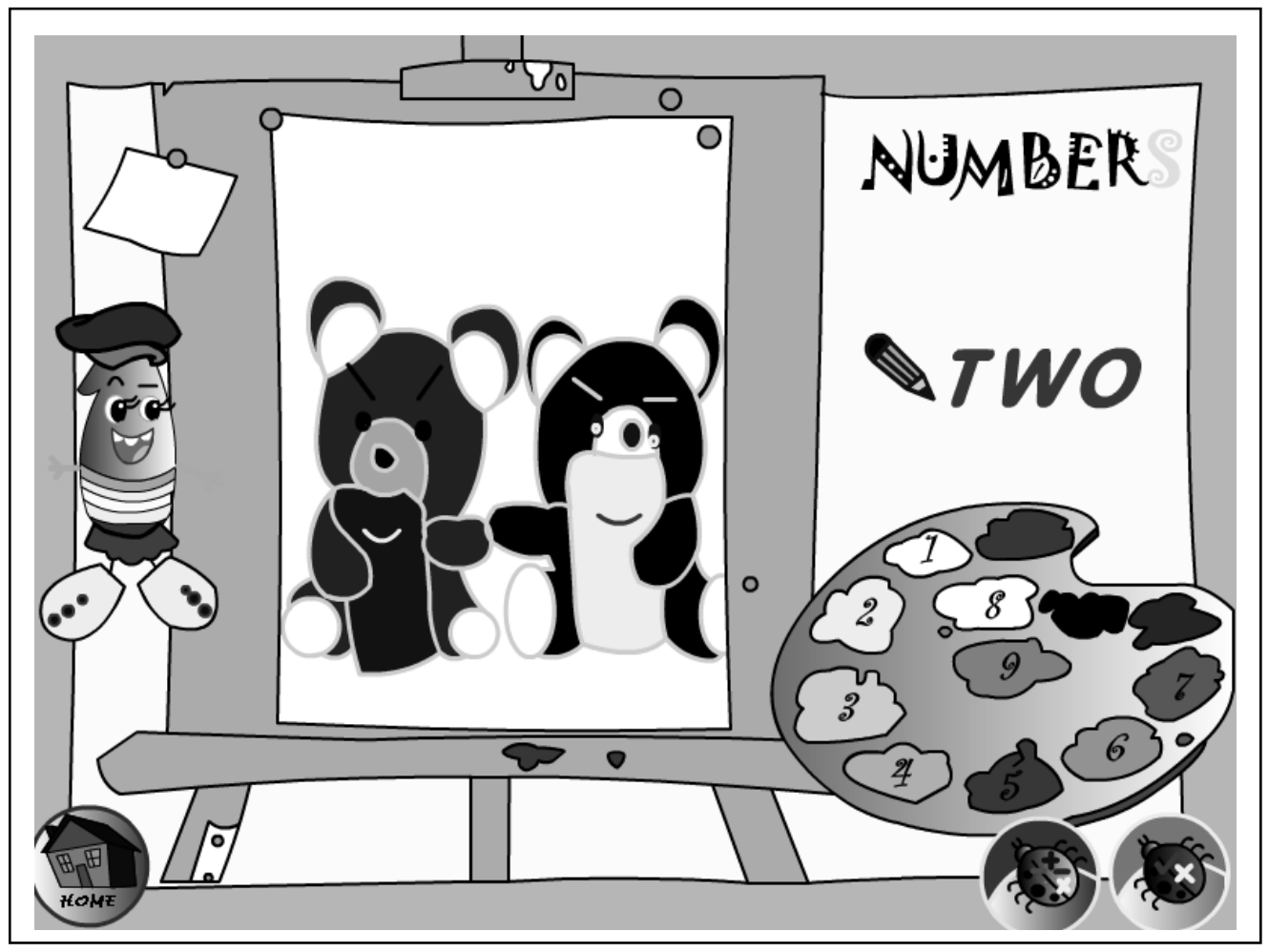

Figure 3. Interface of Subtraction Operation 


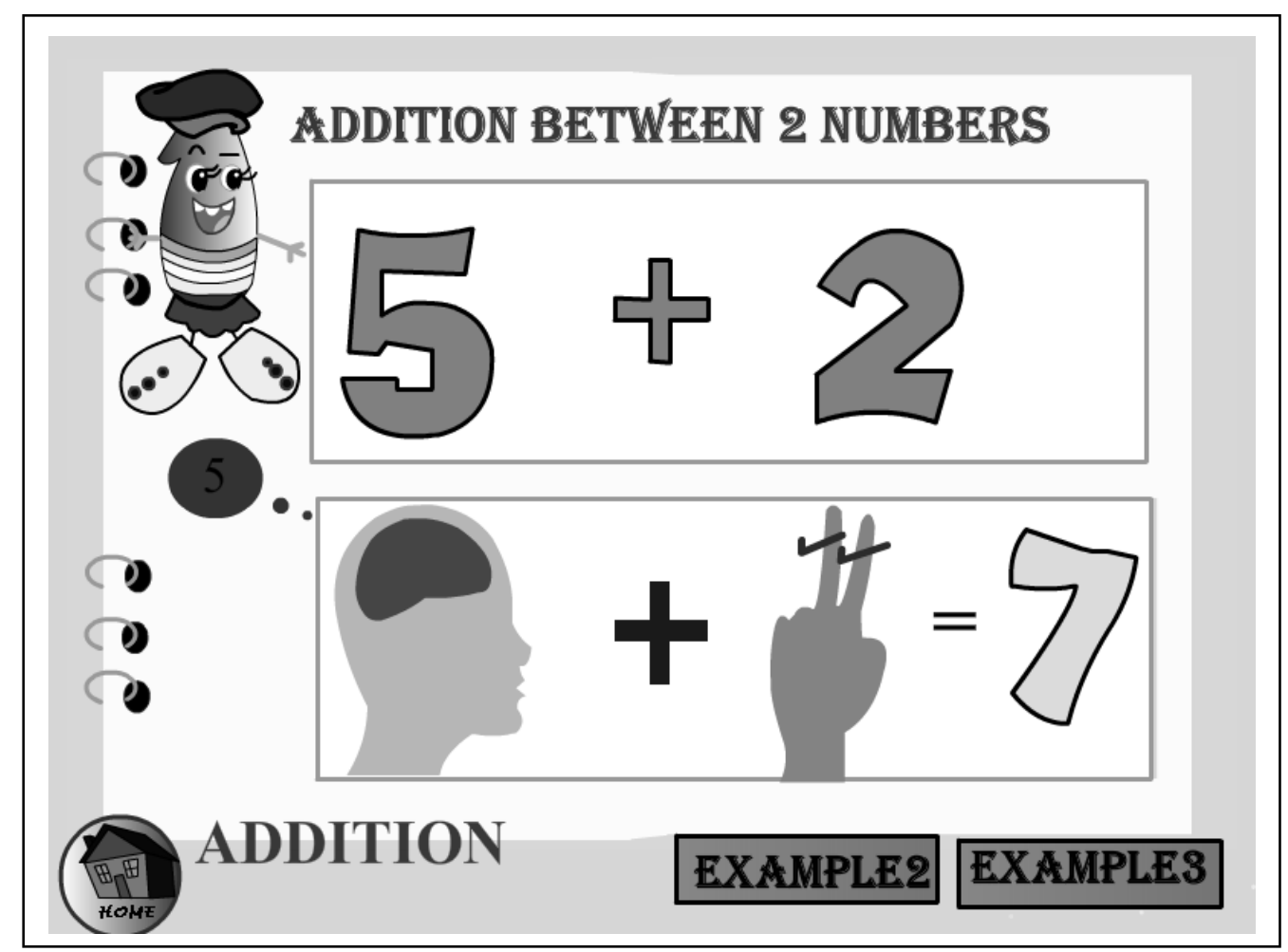

Figure 4. Interface of Mental Arithmetic Technique Implementation

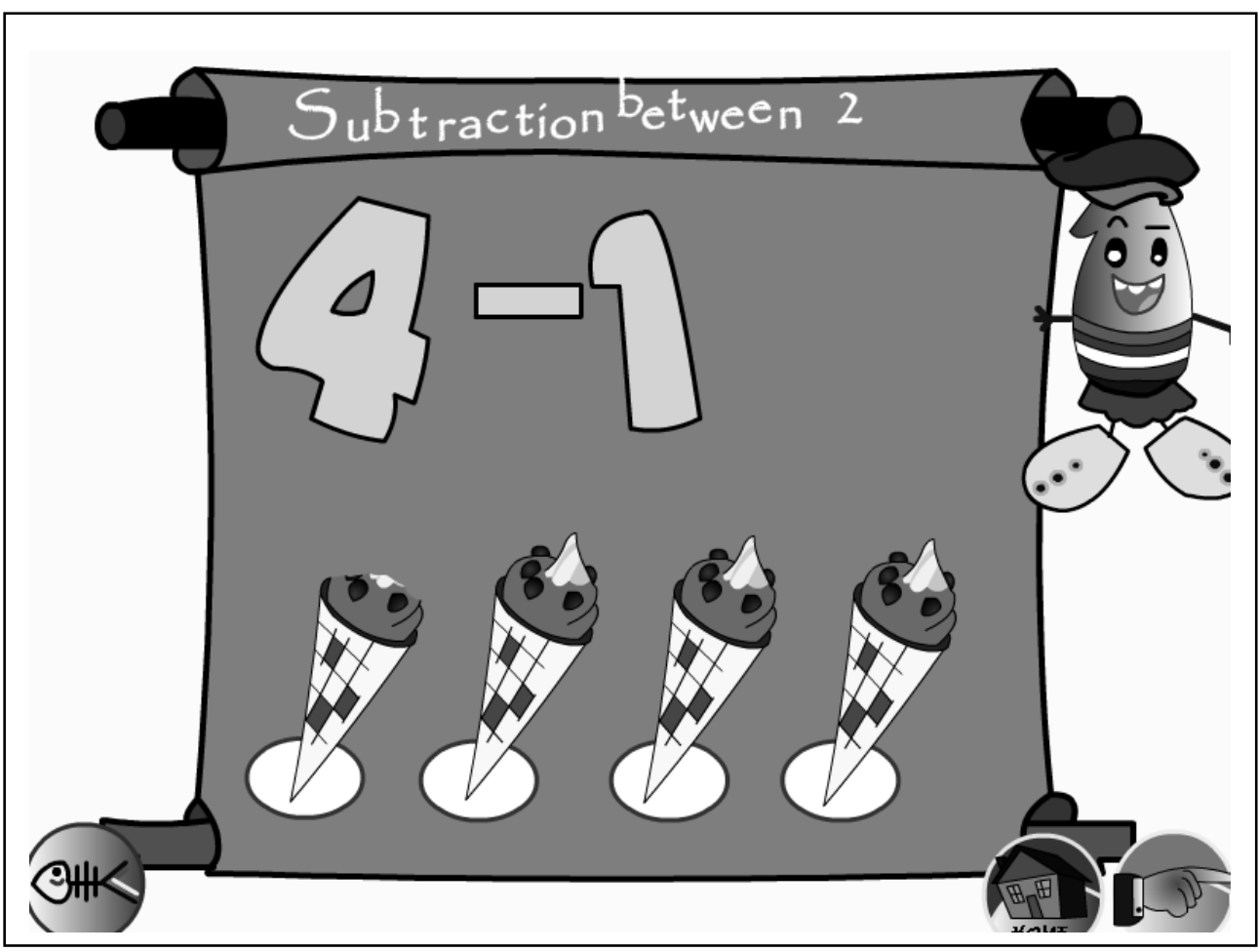

Figure 5. Interface of Subtraction Operation 


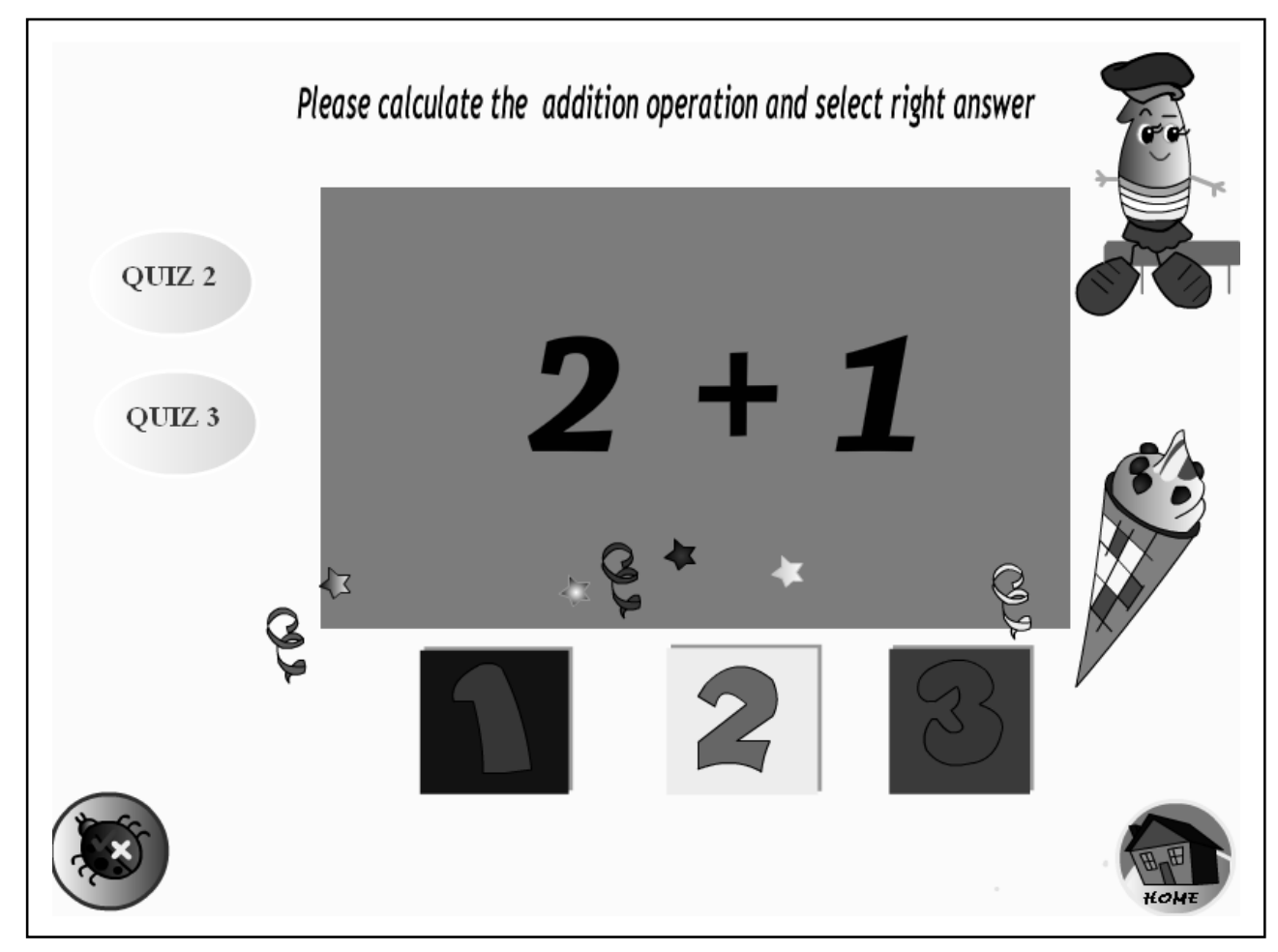

Figure 6. Interface of Quiz Page

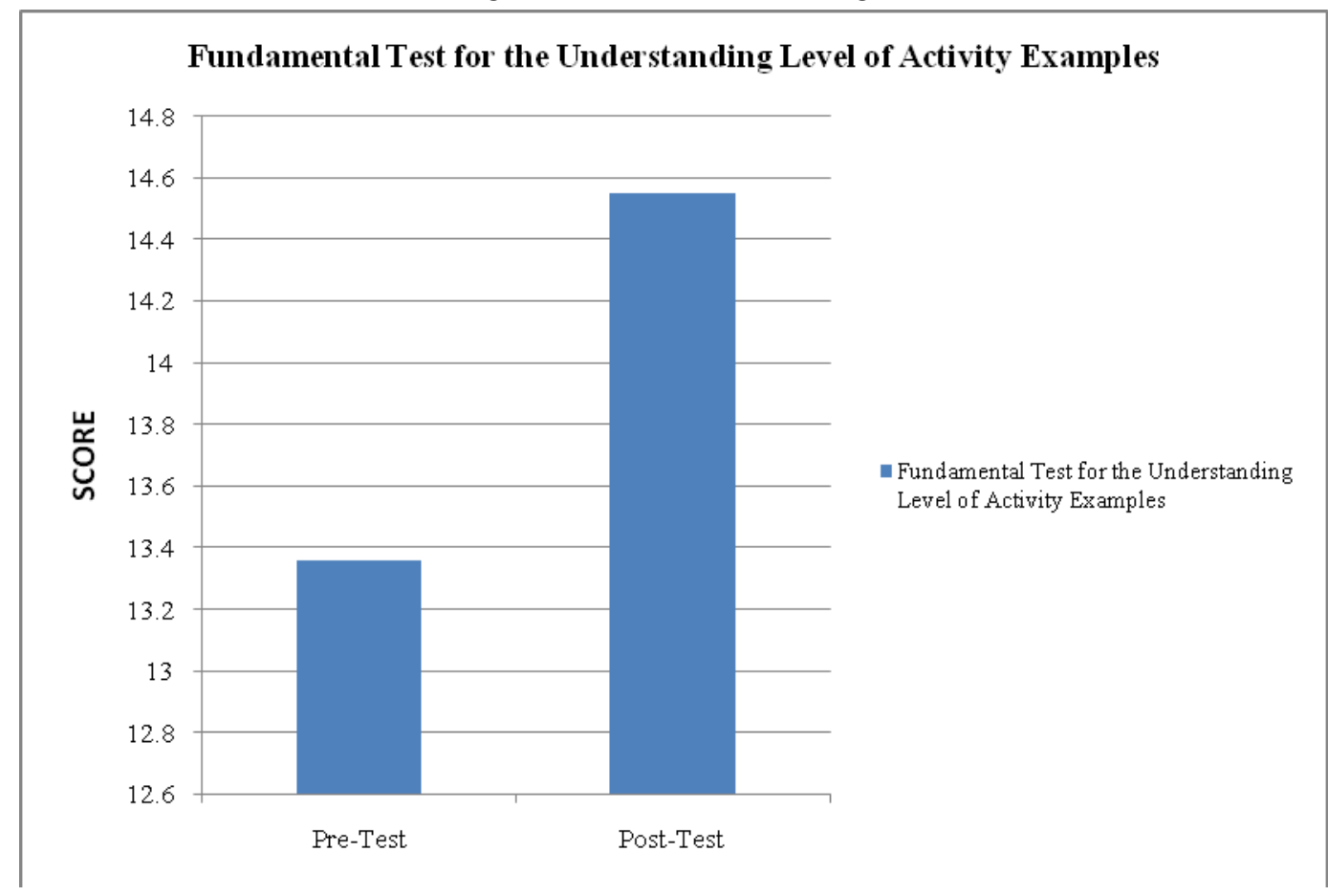

Figure 8. Mean Score of Understanding Level of Activity Examples 


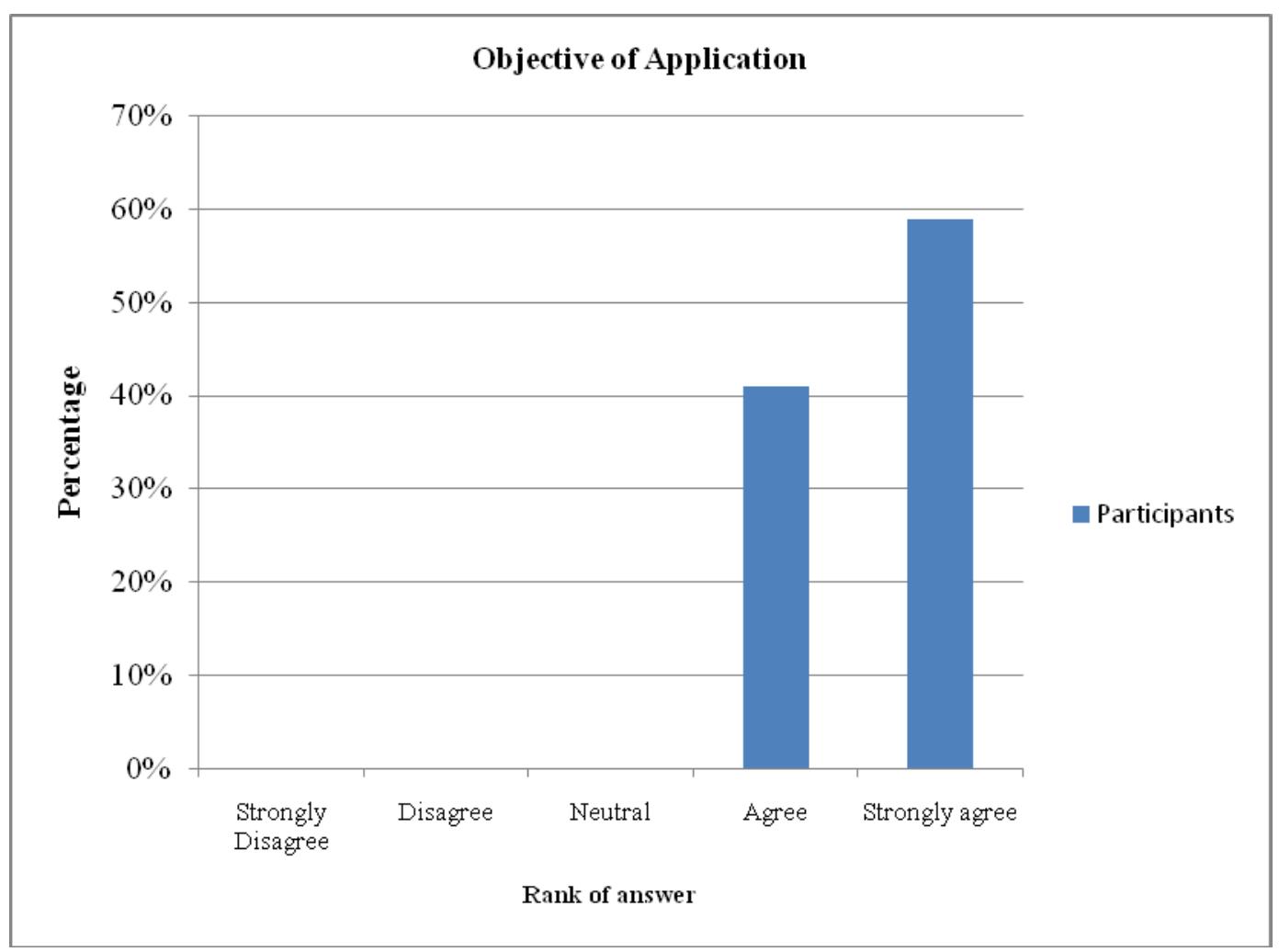

Figure 9. Percentage of Responses of Application Objective Achievement. 